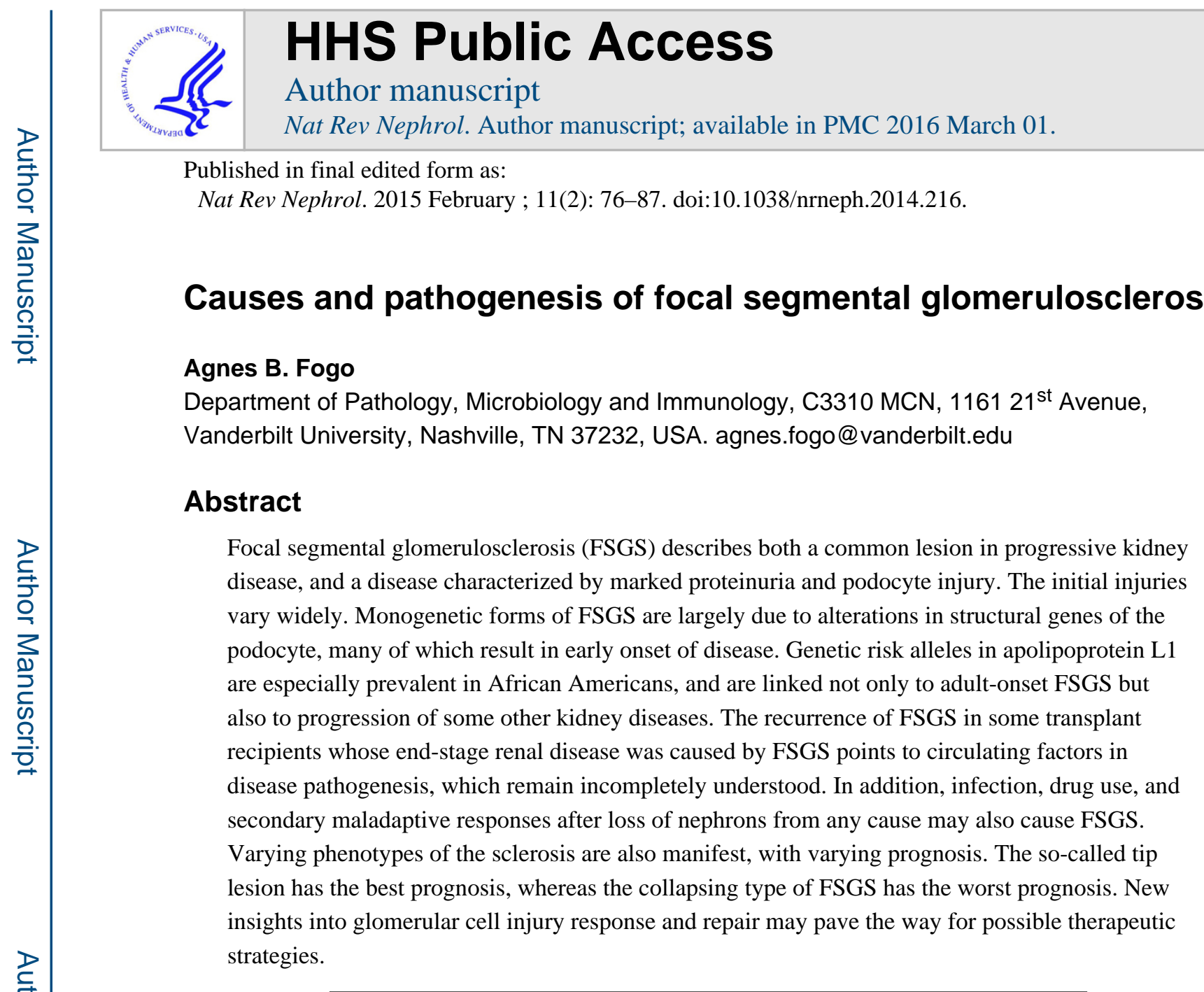

\title{
Introduction
}

The term focal segmental glomerulosclerosis (FSGS) is used to describe both a disease characterized by primary podocyte injury, and a lesion that occurs secondarily in any type of chronic kidney disease (CKD). Classically, 'glomerulosclerosis' is used to describe a lesion of obliteration of capillary lumina by matrix. The focal distribution of sclerosis (involving some, but not all, glomeruli) and the segmental pattern (affecting only a portion of the glomerular tuft) distinguishes scarring related to specific diseases from nonspecific global sclerosis (that is, sclerosis of an entire tuft) that can occur at any age and increases with ageing. However, a focal and segmental pattern of scarring is not unique to diseases with primary podocyte injury, and some of these diseases, such as HIV-associated nephropathy, show alternate light microscopic patterns of lesions, such as collapse of the tuft and overlying cell hyperplasia (Figure 1). The spectrum of segmental lesions is caused by a variety of genetic risk factors and insults, such as circulating factors, infections, drug use and secondary maladaptive responses. Here, I review the causes and pathogenesis of primary and non-immunologic adaptive secondary types of FSGS.

Competing interests

The author declares no competing interests. 


\section{Clinical setting}

Primary FSGS - resulting from podocyte injury - is the most common cause of nephrotic syndrome in US adults, and accounts for about $4 \%$ of end-stage renal disease (ESRD). ${ }^{1}$ The lesions are characterized by focal involvement in a segmental pattern. FSGS frequently manifests as nephrotic syndrome but is much less responsive to steroid therapy than is minimal change disease (MCD): about 50\% of patients with FSGS respond, whereas almost all children with MCD have remission within 8 weeks of therapy, and about $80 \%$ of adults with MCD respond, albeit after longer and more intensive therapy. ${ }^{2,3}$

FSGS recurs in the renal transplant in 30-40\% of patients and manifests with early abrupt onset of nephrotic syndrome and foot-process effacement progressing to overt sclerosis within weeks. ${ }^{4}$ Plasmapheresis has been successfully used to treat a number of transplant recipients with early recurrence of FSGS..$^{5}$ Interestingly, successful retransplantation of a kidney allograft from a patient with recurrent primary FSGS who did not respond to therapy to a patient whose primary kidney disease was not FSGS, has been reported. ${ }^{6}$ The transplanted kidney was removed from the first patient at day 14 and functioned well in the second recipient without proteinuria and with restoration of the effaced foot processes that were present when the kidney was in place in the first patient. These data support a causative role of circulating factors in recurrent FSGS. ${ }^{7}$

\section{Pathologic classification}

Glomerulosclerosis has a wide spectrum of morphological appearances. In 2004, my colleagues and I proposed a working classification to test the possible importance of these diverse morphological patterns of FSGS. ${ }^{8}$ This classification includes five types of lesions: FSGS not otherwise specified (NOS), collapsing variant, tip variant, cellular variant and perihilar variant (Figure 1, Table 1). As varying forms of lesions may coexist in the same biopsy sample, we proposed a hierarchical classification. The collapsing variant is diagnosed if at least one glomerulus shows a collapsing lesion. In the absence of collapsing lesions, tip lesions are sought, and if present without hilar lesions, the tip variant of FSGS is diagnosed. In the absence of the above special types, cellular lesions are sought, and if present, this variant is diagnosed. If most of the segmental lesions are at the vascular pole, the hilar variant is diagnosed. The usual type of sclerosis, or a mix of hilar and tip lesions, are diagnosed as usual-type FSGS.

Patients with the collapsing variant of FSGS have the worst outcomes and less frequent remission of proteinuria, whereas those with the tip variant do much better and respond more frequently to various immuno-suppressive treatments. ${ }^{9-13}$ The perihilar variant is least often associated with full-blown nephrotic syndrome, and is postulated to represent an adaptive response to other injuries that cause scarring and loss of functioning nephrons. Lesions can also change over time, with all subtypes usually evolving to a NOS phenotype as the kidney approaches ESRD. Fidelity of type of FSGS was usually, but not invariably, seen with recurrence of FSGS in the transplant in one case series, whereas another study found no such correlation. ${ }^{14,15}$ With progressive scarring, all lesions may evolve into the FSGS NOS type. None of the lesions are pathognomonic for a primary type of FSGS and 
secondary aetiologies must be excluded. ${ }^{16}$ Morphologic features that suggest a secondary aetiology are low levels of foot-process effacement or other findings of secondary injury, such as the patchy geographic pattern of scarring seen with chronic pyelonephritis, the more severe vascular sclerosis and solidified global glomerulosclerosis seen with arterionephrosclerosis, or increased lamina rara interna by electron microscopy—a sign of endothelial injury.

Additional analysis of the importance of these morphologic subtypes was undertaken in the NIH FSGS Clinical Trials cohort of 138 patients with steroid-resistant primary FSGS. ${ }^{17}$ The trial participants were randomly assigned to receive mycophenolate mofetil and dexamethasone versus cyclosporine, in addition to standard angiotensin-converting-enzyme (ACE) inhibitor or angiotensin-receptor blocker (ARB) therapy. No differences according to treatment arm were observed. However, the worst responses to therapy were seen in patients with collapsing glomerulopathy and the best in those with the tip lesion, with intermediate results for those with FSGS NOS. These findings are even more remarkable considering that all participants had failed steroid treatment. Thus, patients with tip lesions who had failed steroid therapy were unusual compared with the tip-lesion FSGS population as a whole, as these lesions typically respond better to steroids than other types of FSGS. However, steroid-resistant patients with tip lesions still showed better outcomes than those with other types of FSGS.

\section{Causes}

FSGS is a heterogeneous disease. In addition to circulating factors, various injuries may cause focal and segmental sclerosis. The term primary FSGS is used for patients with primary podocyte injury (so-called podocytopathy), which is most often caused by a circulating factor. Segmental scars due to other causes are typically designated as secondary FSGS. These lesions can develop as a result of severe immune complex diseases, necrotizing crescentic pauci-immune glomerulonephritis, arterionephrosclerosis, chronic pyelonephritis or any injury that results in a substantial decrease in nephron number. They can even occur secondary to severe advanced primary tubulointerstitial diseases, such as chronic obstruction or pyelonephritis. Specific immunofluorescence and electron microscopic studies, along with analysis of the type of sclerosis in conjunction with the clinical history, can distinguish many of these specific underlying aetiologies. ${ }^{16}$

Familial and sporadic forms of FSGS have both been linked to mutations in key podocyte molecules (Table 2). ${ }^{18}$ Additional genetic susceptibilities might increase the severity of the resulting injury after second hits, such as drug-induced injury, infection or the mal-adaptive alterations that occur after any loss of kidney parenchyma. These maladaptive processes include haemodynamic alterations, increased growth factors and oxidative stress.

\section{Circulating factors}

Several circulating factors have been proposed to cause FSGS, including cardiotrophin-like cytokine-1 (CLC-1) and soluble urokinase plasminogen activator receptor (suPAR). ${ }^{7}$ Although CLC-1 is inactivated by galactose, use of galactose infusion to inhibit recurrence of FSGS has not been uniformly successful. ${ }^{19}$ 
Urokinase plasminogen activator surface receptor (UPAR) is a membrane protein that can bind urokinase-type plasminogen activator, vitronectin and integrins. Cleavage of uPAR and glycosylation of the resulting fragments yield various circulating suPAR fragments. In mice lacking UPAR, treatment with or overexpression of suPAR was linked to increased av $\beta 3$ integrin signalling in podocytes, with resulting foot-process effacement and proteinuria. ${ }^{20}$ These effects were prevented by treatment with a uPAR-specific antibody.

As suPAR is an acute phase reactant, its levels are increased in inflammatory conditions. ${ }^{21}$ In a cohort study, circulating suPAR levels were increased in $70 \%$ of patients with FSGS, versus only $6 \%$ of individuals in the control group. ${ }^{20,21}$ However, serum suPAR levels were also increased in patients with secondary FSGS 22 and did not differ between children with FSGS and those with other kidney diseases. ${ }^{23}$ Furthermore, serum uPAR levels were increased in all kidney transplant patients regardless of their primary kidney disease ${ }^{24} \mathrm{In}$ several studies of patients with glomerular disease, serum suPAR levels inversely correlated with estimated glomerular filtration rate (eGFR). ${ }^{25}$ Moreover, suPAR levels in patients grouped according to eGFR did not discriminate those with primary FSGS from those with other renal diseases. ${ }^{25}$ Similar levels of suPAR have also been reported in children with MCD and in those with FSGS. ${ }^{26}$

Whether specific glycosylated cleavage products of suPAR could be sensitive and specific markers of FSGS, or potential mediators of disease, remains unproven. Furthermore, the particular triggers for development of pathologic circulating factors are not yet known. Interestingly, rituximab (a chimeric monoclonal antibody against CD20, which is expressed on B cells) has shown benefit in reducing incidence of relapses in some children and adults with FSGS. ${ }^{27}$ Whether this reduction could be the result of effects of rituximab on B cells, or direct effects on podocytes that protect the cytoskeleton and prevent apoptosis, is not known. ${ }^{27}$

\section{Genetic causes and epigenetic risk factors}

Mutations and allele variants-Mutations in various key podocyte genes have been identified in familial FSGS (Table 2). Children with steroid-resistant nephrotic syndrome (SRNS) are often screened for mutations in the NPHS1 gene, which encodes nephrin, and/or the NPHS2 gene, which encodes podocin, because of the fairly high frequency of these mutations in this population. Patients with mutations in NPHS1 and/or NPHS2 have a reduced response to steroids and a reduced risk of FSGS recurrence. ${ }^{28}$ In some case series, a surprisingly high proportion (about $25 \%$ ) of paediatric patients with steroid-resistant, nonfamilial forms of FSGS had NPHS2 mutations. ${ }^{29}$ Mutations in the $C D 2 A P$ gene that encodes $\mathrm{CD} 2$-associated protein, which links the slit diaphragm proteins to the cytoskeleton, have been detected in a few adult patients with proteinuria and FSGS without a family history of the disease. ${ }^{30,31}$ NPHS2 mutations have been very rarely detected in patients with adultonset steroid-resistant FSGS and mutations in additional podocyte-related genes have been identified in rare cases of familial FSGS (Table 2) ${ }^{2,32}$ These families have adult onset and variable penetrance, supporting the hypothesis that additional second hits contribute to the overt disease phenotype. 
The spectrum of the structural genes of the podocyte involved in FSGS points to the key importance of the cytoskeleton and slit diaphragm in maintaining podocyte integrity and functionality. Of note, specific mutations do not uniformly result in a distinct morphological phenotype, indicating that additional modifying factors influence the disease phenotype. In a family with ACTN4 mutation, two siblings developed differing forms of FSGS at the time of biopsy, one with collapsing lesions and the other with the common NOS type of sclerosis. ${ }^{33}$ Whether these differences reflect differing time points in an evolution of lesions or variations in additional environmental, genetic or epigenetic modifiers of injury is not known.

In contrast to children with SRNS or FSGS, adults with nonfamilial FSGS very rarely have an identifiable monogenic cause of disease. ${ }^{23}$ Mutations in INF2 were present in 20 of 215 (9\%) families with autosomal-dominant nephrotic syndrome or FSGS, but only 2 of 288 $(0.7 \%)$ families with sporadic FSGS. Mutations in ACTN4 and TRPC6 were slightly more common, present in $3 \%$ and $2 \%$ of families with sporadic forms of FSGS, respectively. Thus, searching for mutations in adults with non-familial forms of FSGS has a very low likelihood of yielding a causative gene abnormality.

Polygenic influences also modulate susceptibility to FSGS. Different animal strains and human populations show varying susceptibilities to development of the disease. For example, C57 black mice are highly resistant to multiple models of glomerulosclerosis, although they do develop tubulointerstitial fibrosis after unilateral ureteral obstruction. ${ }^{34} \mathrm{By}$ contrast, $129 \mathrm{SV}$ and some other mice strains are susceptible to the development of glomerulosclerosis. The gene that encodes transforming growth factor (TGF)- $a$, a ligand for epidermal growth factor receptor, was linked to these differences in risk. ${ }^{35}$ Interestingly, $\mathrm{Balb} / \mathrm{c}$ mice are susceptible to the development of FSGS after adriamycin injection, whereas other strains are resistant. ${ }^{36} \mathrm{Balb} / \mathrm{c}$ mice are deficient in Prkdc, the protein kinase, DNAactivated, catalytic polypeptide subunit, which has a key role in DNA repair. In these mice, DNA repair is deficient after injection of adriamycin, which directly intercalates in the podocyte DNA. Whether similar susceptibilities to second-hit toxins exist in humans is unknown.

The incidence of FSGS is increased in family members of patients with FSGS without monogenic inheritance patterns, and is more common in African Americans than in Caucasians. Apolipoprotein L1 (APOL1) allele variants were first linked to increased risk of development of FSGS, HIV-associated nephropathy and hypertension-associated arterionephrosclerosis in African Americans, and might also contribute to increased risk of diabetic nephropathy in this population. ${ }^{37}$ The APOL1 risk allele variants $\mathrm{G} 1$ and $\mathrm{G} 2$ are much more frequent in African Americans than in Caucasians, among whom the APOL1 variant G0 is most common. ${ }^{38}$ Interestingly, $A P O L 1$ risk allele variants have antitrypanosomal activity; this protective effect might have provided evolutionary pressure that could explain the increased prevalence of these variants in people living in sub-Saharan Africa. ${ }^{38}$ The APOL1 gene product is expressed in numerous cell types, including platelets, monocytes and podocytes. However, the mechanisms by which the risk allele variants might have a causal role and increase the risk of kidney disease remain unknown. 
MicroRNAs-MicroRNAs (miRNAs) are a diverse group of short, non-coding singlestranded RNA molecules that bind to partially or fully complementary sequences and may inhibit translation or destabilize transcripts. They can also modulate FSGS. For example, overexpression of miRNA-193A in transgenic mice led to foot-process effacement, FSGS and de-differentiation of podocytes with loss of expression of Wilms tumour protein (WT1), podocalyxin and nephrin. ${ }^{39}$ MiRNA-193A was expressed in the normal mouse mostly in parietal epithelial cells (PECs) and only occasionally in podocytes. Elegant murine transplant studies showed that the miRNA-193A-induced phenotype was not caused by a circulating factor. In cultured podocytes, overexpression of miRNA-193A caused injury, and was rescued by WT1 overexpression. In vivo, treatment with a miRNA-193 antagonist resulted in reduced albuminuria and better preserved podocytes. Levels of miRNA-193A were increased in patients with idiopathic FSGS (regardless of subtype) and in some patients with HIV-associated FSGS, but not in those with genetic causes of FSGS. ${ }^{39}$ Podocyte expression of miRNA-193A was high in patients with FSGS, contrasting with low expression in those with MCD.

MiR-324-3P has been implicated in renal fibrosis. Targets of this miRNA include prolyl oligopeptidase (POP), which mediates breakdown of thymosin $\beta 4$ to the antifibrotic tetrapeptide $\mathrm{N}$-acetyl-seryl-aspartyl-lysyl-proline (Ac-SDKP). ${ }^{40,41}$ Thymosin $\beta 4$ is a Gactin-sequestering protein with wide-ranging functions including roles in cell migration, angiogenesis and extracellular matrix synthesis, some of which might be receptor mediated. Ac-SDKP is degraded by ACE and its levels are increased in response to ACE inhibition. ${ }^{42}$ In animal studies, upregulation of miR-324-3P was associated with decreased levels of POP in glomeruli and tubules, reduced urine levels of Ac-SDKP and increased fibrosis.

Treatment with ACE inhibitors reduced expression of this miRNA, augmented levels of POP and consequently Ac-SDKP, and decreased fibrosis. ${ }^{42}$

Additional miRNAs have been implicated in podocyte injury. For example, podocyte expression of miR-30 is reduced in patients with FSGS and injured cultured human podocytes can be rescued by exogenous miR-30. ${ }^{43}$ This miRNA inhibits Notch1 and p53, which might both have roles in podocyte injury. Gluocorticoid treatment maintained miR-30 expression in cultured injured podocytes, and in the podocytes of puromycin aminonucleoside (PAN)-treated rats. Moreover, exogenous miR-30 reduced PAN-induced podocyte injury in vivo ${ }^{43}$ and TGF- $\beta$-induced podocyte apoptosis was dependent on downregulation of miR-30 by Smad- $2 .{ }^{44}$

\section{Drugs}

Illicit and therapeutic drugs have been implicated in the development of FSGS. ${ }^{2,45}$ Classically, heroin was associated with FSGS, although the actual injurious agents might have been adulterants of this street drug rather than the pure compound. ${ }^{2}$ The development of FSGS has been reported in a small number of patients who received exogenous interferon therapy. ${ }^{46}$ Pamidronate and other bisphosphanates can also cause FSGS. ${ }^{47}$ Some patients who received these drugs developed nephrotic syndrome and FSGS lesions, usually of the collapsing variant, with an improvement when the drug was removed and recurrence when it was reinstituted. 
Calcineurin inhibitors have direct effects on the podocyte actin cytoskeleton. ${ }^{48}$ As calcineurin causes synaptopodin dephosphorylation, enabling degradation of synaptopodin, calcineurin inhibitors are typically protective of podocytes. However, in some patients, de novo collapsing lesions of FSGS in renal allografts have been linked to cyclosporine use. ${ }^{49}$ These lesions are postulated to be the result of severe ischaemia induced by calcineurin inhibitors, potentially via induction of endothelin and perturbation of the vasoactive balance in the kidney. ${ }^{50}$

De novo FSGS lesions in transplanted kidneys may also occur with sirolimus, an inhibitor of the mammalian target of rapamycin (mTOR) pathway. As mTOR is crucially important for podocyte development, ${ }^{51,52}$ too much or too little mTOR activation results in podocyte lesions and proteinuria. Particularly with underlying growth stimuli, such as with a single transplanted kidney, or in patients with diabetes mellitus and other hypertrophic stimuli, treatment with mTOR inhibitors may cause podocyte derangement and FSGS. Exogenous anabolic steroids have also been linked to FSGS, typically hilar-type lesions (which are likely the result of haemodynamic and/or growth perturbations) and less commonly, collapsing lesions. These lesions typically improve on cessation of the drugs. ${ }^{53}$

\section{Infections}

HIV infection can cause collapsing glomerulopathy with accompanying microcystic tubular changes and active tubulointerstitial inflammation. ${ }^{54}$ This injury is related to direct infection of renal parenchymal cells and dependent on the HIV structural proteins Nef and Vpr. ${ }^{55-58}$

The type of sclerosis is modified by the genetic background in experimental models and also likely in humans. C57 black mice that overexpressed HIV proteins showed the usual type of sclerosis, whereas more susceptible mixed background strains showed collapsing glomerulopathy. ${ }^{57}$ Among patients infected with HIV, African Americans much more commonly develop a collapsing form of FSGS, whereas usual type FSGS, mesangioproliferative disease and even MCD are more commonly seen in Caucasians. ${ }^{54,59}$ However, among patients with HIV-associated nephropathy, pathologic lesions are similarly severe in those who do or do not express the APOL1 G1 or G2 risk alleles. ${ }^{59}$ These findings indicate that additional injuries and underlying susceptibility factors beyond APOL1 variants contribute to the FSGS phenotype and severity in HIV-infected patients.

Parvovirus B19 has also been epidemiologically linked to FSGS, particularly the collapsing variant, but direct causal evidence for its involvement with FSGS lesions is incomplete. ${ }^{60}$ Some patients have also shown FSGS lesions when infected with cytomegalovirus, EpsteinBarr virus or simian virus $40 .^{2}$

\section{Pathophysiological mechanisms}

\section{Responses to decreased nephron mass}

CKD manifests an inexorable progressive vicious cycle, set in motion when nephrons undergo initially adaptive but ultimately maladaptive changes, culminating in further sclerosis. These changes include haemodynamic alterations, abnormal growth factors, and increased oxidative stress. Initial findings from the 5/6 nephrectomy rat model of CKD focused on haemodynamic derangements as the key factor in the vicious cycle of disease 
progression. ${ }^{61-63}$ In particular, glomerular hypertension was implicated in the progression of glomerular scarring. However, serial micropuncture experiments showed that in this model, the degree of scarring in individual glomeruli did not correlate linearly with the maximal or total burden of glomerular haemodynamic load. ${ }^{64}$ Thus, numerous additional maladaptive factors, including abnormal growth stimuli, reactive oxygen species and abnormal glomerular hypertrophy, have been postulated.

In 1988, Barker and Osborne reported an association between low birth weight at term (defined as $<2.5 \mathrm{~kg}$ ) and increased risk of cardiovascular disease and hypertension in adulthood. ${ }^{65}$ Brenner and colleagues carried this observation forward to the kidney, observing that patients with low birth weight might have decreased nephron endowment as well as abnormal haemodynamic stresses on the remaining nephrons, and thus be susceptible to additional injury. ${ }^{61,66}$ Thus, low birth weight, whether in term or extremely preterm babies, is also associated with an increased risk of CKD and FSGS. ${ }^{67,68}$ Low birth weight and an increased incidence of CKD in adulthood were observed in patients born during the Dutch famine in World War II. ${ }^{69}$ In a small Japanese study, low birth weight was more common in patients with FSGS than in the general population (38\% versus $10 \%) .{ }^{70}$ The patients with low birth weight and FSGS were all preterm, and their biopsy samples showed decreased numbers of WT1-expressing glomerular cells, compared to patients with MCD or FSGS and normal birth weight. Thus, prematurity may particularly impair podocyte development and result in reduced podocyte density. In experimental models, exposure of neonatal mice to PAN at day 1 after birth, which directly injures podocytes, resulted in pups with podocyte depletion and increased hypertension and sclerosis in later life. ${ }^{71}$

Various populations show different nephron endowments, with a large normal range (mean of 1,000,000 nephrons, range of 300,000-1,300,000 nephrons per kidney). ${ }^{72}$ Among young adult men who unexpectedly died due to trauma and were matched according to age and body mass index, larger nephrons, likely reflecting lower nephron number, were observed in African Americans than in Caucasians. ${ }^{73}$ Studies of the Aboriginal Australian population also document very small numbers of nephrons with glomerulomegaly linked to CKD. ${ }^{74}$ Oligomeganephronia is characterized by few but very large nephrons at birth, and increased incidence of FSGS. ${ }^{75}$ In patients with unilateral renal agenesis, the remaining kidney seems not to have the full complement of nephrons. These patients show a marked increase in the development of microalbuminuria and hypertension, both compared to the normal population and to patients who have had one kidney removed at a very young age because of Wilms tumour. ${ }^{76}$ Thus, the age at which nephrons are lost, and the remaining complement of nephrons, might both be crucial in determining whether adaptive growth responses culminate in sclerosis or maintenance of renal function. In addition to greater haemodynamic stress placed on remaining nephrons, changes in utero may, through epigenetic mechanisms, alter responses to subsequent injuries, setting up a two-hit model for increased susceptibility to development of FSGS.

Profound growth stimuli and haemodynamic stimuli may also occur in settings where nephron number is initially normal. An acquired reduction in nephron mass, whether due to parenchymal disease or surgery (for bilateral infections or tumours), has been associated with increased incidence of FSGS. ${ }^{16}$ The largest glomeruli observed in humans are those in 
patients with sickle cell anaemia, in whom chronic hypoxia is presumed to stimulate glomerular hypertrophy. ${ }^{75}$ Glomerulomegaly is also present in patients with sleep apnoea, cyanotic congenital heart disease and obesity. Obesity-associated FSGS sclerotic lesions are often perihilar, and patients may improve with bariatric surgery even before weight loss occurs. ${ }^{77,78}$ Changes in key adipogenic hormones or redox state have therefore been postulated in these patients. Marked glomerulomegaly is also present in early FSGS in biopsy samples that show foot-process effacement without diagnostic segmental sclerotic lesions, with later biopsies confirming development of overt FSGS. ${ }^{63}$ Even at this early stage before sclerosis is evident, proteomic profiles differ from normal in experimental models of FSGS, and gene expression profiles robustly separate MCD and FSGS in human biopsy samples. ${ }^{79,80}$ Putative pathways that are activated early in the disease process include those related to podocyte injury, reactive oxygen species and impairment of autophagy.

\section{Profibrotic molecules}

In general, FSGS and CKD are characterized by increases in profibrotic molecules compared to those of healthy individuals or patients with nonprogressive proteinuric diseases such as MCD. Many classic profibrotic molecules have multiple effects; they act directly on glomerular parenchymal cells, infiltrating monocytes and macrophages as well as on systemic parameters such as blood pressure. These molecules include angiotensin, the effects of which are mediated through the classic pro-fibrotic type 1 angiotensin II (AT1) receptor, the counter-regulatory type 2 angiotensin II (AT2) receptor, TGF- $\beta$, plasminogen activator inhibitor-1 (PAI-1) and others.

In addition to haemodynamic effects, angiotensin mediates direct increases in matrix and promotes podocyte injury via the AT1 receptor. ${ }^{81}$ Conversely, the AT2 receptor, when activated, promotes podocyte maintenance. ${ }^{82}$ TGF- $\beta$ directly induces podocyte injury in culture. ${ }^{83}$ PAI- 1 is induced by both angiotensin and TGF- $\beta$; this inhibitor of tissue-type and urokinase-type plasminogen activators prevents formation of plasmin from plasminogen. ${ }^{84}$ Plasmin has numerous effects, not only lysing fibrin, but a variety of matrix proteins. Thus, high levels of PAI-1 inhibit matrix turnover and degradation and promote sclerosis. Increased PAI-1 levels are tightly linked to development of sclerosis in animal models and in various human diseases, including FSGS. ${ }^{85}$ Progressive kidney diseases, including FSGS, show decreased activity of proteolytic pathways, increased profibrotic inflammatory cells (such as M1 macrophages), and increased expression of downstream molecules (such as connective tissue growth factor). ${ }^{86}$ These mechanisms converge to ultimately stimulate increased extracellular matrix synthesis and decreased turnover of matrix with loss of parenchymal cells.

\section{Cell injury versus repair}

In FSGS, perturbation of multiple cell types occurs, with increases in mesangial matrix, loss of endothelial cells, obliteration of capillary lumens by sclerosis and podocyte derangement ranging from foot-process effacement to proliferation of visceral epithelial cells. Interactions between podocytes and the underlying glomerular basement membrane (GBM) are important for maintenance of the filtration barrier. Dystroglycan is an integral component of the GBM. Patients with MCD showed decreased dystroglycan staining in renal biopsy 
samples, whereas dystroglycan expression was maintained in the non-sclerotic segments of biopsy samples from patients with usual type FSGS. ${ }^{87,88}$ The heterogeneity of the state of the podocytes was illustrated by a marked decrease or loss of dystroglycan staining in biopsy samples from patients with collapsing FSGS. ${ }^{89}$

The podocyte has a limited, if any, ability to proliferate, and podocyte loss is tightly linked to development of glomerulosclerosis. Loss of podocytes can occur by necrosis (rare), detachment of viable podocytes, apoptosis or by 'catastrophic mitosis' when failed attempts to divide result in podocyte de-differentiation and loss of adhesion to the underlying GBM. ${ }^{90}$ As detachment leads to denuded areas of GBM, remaining podocytes that cannot proliferate stretch and move to cover the gap. However, although podocytes are mobile, their ability to hypertrophy and cover such gaps is limited. The remaining over-stressed podocytes may then undergo secondary injury and also be lost. Eventually, denuded areas of GBM may give rise to adhesions and the development of sclerosis (Figure 2). ${ }^{91}$

In transgenic rats with podocyte-specific expression of the human diphtheria toxin receptor, podocyte injury after injection of diphtheria toxin is dose related. In these rats loss of $>20 \%$ of podocytes resulted in sclerosis, whereas repair could occur with lesser degrees of podocyte depletion..$^{92}$ Even if some podocytes are initially spared from injury, adverse effects on the remaining intact podocytes may occur. In studies of chimeric mice in which only a subpopulation of podocytes expressed the human CD25 receptor, which binds a modified pseudomonas exotoxin, injury spread from the initially injured podocytes that expressed the receptor to those that did not express the receptor. ${ }^{93}$ Ultimate sclerosis depended on the degree of spreading of injury. When mice that expressed the toxin receptor on all podocytes had one kidney protected from additional filtration work by obstructing the ureter after initial toxin injury, no sclerosis occurred in the obstructed kidney. ${ }^{94}$ By contrast, the unobstructed kidney, which was equally exposed to the toxin, showed severe sclerosis. Together, these data indicate that not only does podocyte injury affect the remaining podocytes, but that podocytes may be protected and sclerosis reduced if the kidney is put to 'bed rest' and second hits are avoided. The exact mechanisms of the observed protectionand the possible translation to human disease-await further study.

Podocytes are key to the health of glomerular endothelial cells. They are the source of vascular endothelial growth factor (VEGF), which binds VEGF receptor 1 and 2 (also known as flk-1 and flt-1, respectively) on endothelial cells. Selective knockout of VEGF in podocytes results in death of glomerular endothelial cells and thrombotic microangiopathy ensues. ${ }^{95}$ Correspondingly, some patients treated with bevacizumab, an antibody to VEGF, develop thrombotic microangiopathy. Conversely, overexpression of VEGF in podocytes leads to collapsing type glomerulopathy in mice. ${ }^{96}$ Taken together, these findings illustrate the importance of the podocyte for the integrity of the glomerulus.

PECs are potential podocyte progenitors and niche cells that express the stem cell markers CD24 and CD133 and may move around the bend at the vascular pole, populate the glomerular tuft, and thus have a visceral location (Figure 2). ${ }^{97-99}$ Lineage tracing studies have shown that under some conditions PECs may differentiate fully to show a morphologic appearance like that of podocytes. ${ }^{100}$ Thus, cells in a visceral epithelial location might not 
express podocyte markers or be functional podocytes. Visceral epithelial cell is thus a term that describes the anatomical location of an epithelial cell regardless of its differentiation or functionality.

Podocyte renewal from PECs occurs during development and in young mice, and may also occur acutely after diphtheria toxin injection. ${ }^{100}$ However, when injury was the result of nephron loss, murine podocytes underwent hypertrophy rather than regeneration, and no podocyte turnover was found in progressive ageing-related sclerosis. These limitations were linked to accumulation of oxidized protein with subsequent loss of the podocyte. Thus, the timing, magnitude and rapidity of injury may determine the potential of PECs to repopulate podocytes. ${ }^{101}$ Although bone marrow-derived cells have been postulated to give rise to podocytes, ${ }^{102}$ lineage tracing studies indicate that these cells likely do not contribute substantially to podocyte regeneration. ${ }^{103}$

PECs can have adverse effects; migration of these cells onto the glomerular tuft is associated with matrix production and sclerosis in animal models. ${ }^{104}$ PEC progenitors may be increased by treatment with retinoids or ACE inhibitors. ${ }^{105}$ Podocytes are formed during embryonic development from PEC progenitors, and acquire increased cell cycle inhibitors p21, p27, p57, with decreases in cyclin-dependent kinase inhibitor cyclin D1 and Notch. ${ }^{105}$ As WT1 was acquired by the differentiating podocytes, a decrease in levels of paired box protein Pax-2 occurred. ${ }^{105}$ When WT1 differentiation was prevented, activation of the $\beta$ catenin-Wnt pathway occurred, resulting in undifferentiated PECs. Shifting the fate of PECs toward podocyte development by blocking stromal cell-derived factor 1 (also known as C$\mathrm{X}-\mathrm{C}$ motif chemokine 12) resulted in a reduction in proteinuria and increased preservation of podocytes in type 2 diabetic mice. ${ }^{106}$ Similarly, addition of Notch resulted in decreased expression of mesenchymal markers in experimental models of collapsing FSGS. ${ }^{101}$ Overexpression of telomerase reverse transcriptase (TERT), an upstream activator of Wnt, resulted in increased Wnt signalling and collapsing FSGS in mice. ${ }^{107}$ Conversely, silencing of transgeneic TERT expression or treatment with the Wnt inhibitor Dickkopf-related protein 1 normalized the lesions. Increased TERT expression was also observed in the kidneys of patients with FSGS. These findings implicate Wnt balance and the pathways that converge on Wnt signalling as key factors in determining the responses of glomerular epithelial cells to injury.

The Notch family consists of four receptors (Notch 1-4) and six ligands: Jagged1, Jagged2, Delta-like protein (DLL) 1, DLL2, DLL3 and DLL4. Notch activation in podocytes leads directly to podocyte damage and apoptosis. ${ }^{108}$ Aberrant Notch 1 expression induced PEC migration and led to collapsing lesions in transgenic mice. ${ }^{101}$ In a podocyte-specific injury model (NEP25 mice), Notch 1 expression first increased in podocytes and then in PECs. ${ }^{101}$ Parallel investigations in patients with collapsing glomerulopathy also showed the presence of Notch-1 in hyperplastic visceral epithelial cells. When Notch was inhibited, cultured murine PECs showed less response to TGF $\beta$. In vivo, Notch inhibition could prevent the proliferation of murine visceral epithelial cells but did not prevent podocyte loss after injury. These findings indicate that factors beyond Notch also influence podocyte-PEC transitions. 
In the early phase of recurrent FSGS, when only foot process effacement was observed, we showed increased expression of CD44-an adhesion molecule and marker of activated PECs —on the glomerular tufts. ${ }^{109}$ This CD44 activation was not observed in normal kidneys, MCD controls or transplanted kidneys without recurrent FSGS. In collapsing glomerulopathy, proliferating visceral epithelial cells showed loss of podocyte markers including WT1, synaptopodin and podocalyxin, and expressed expression of the proliferation marker antigen KI-67, PEC markers CD44 and claudin and the AT1 receptor. ${ }^{110-112}$ The lack of podocyte markers with acquisition of proliferation markers in these cells was initially interpreted as de-differentiation of podocytes, but subsequent evidence indicates that this phenotype identifies proliferating PECs on the glomerular tuft. ${ }^{9}$ Whether these findings represent migration of PECs from the Bowman capsule to the tuft, or transdifferentiation of visceral epithelial cells in situ of the tuft, has not been shown. Some experimental data support the hypothesis that transition may occur from podocytes to PECS, but not from PECs to podocytes. ${ }^{113}$ However, other lineage tracing studies in mice indicate that in some settings (such as during development or after acute injury, but not after 5/6 nephrectomy or in aging-related sclerosis) PECs may migrate to a visceral location and stain and function as podocytes. ${ }^{114}$

Other sources for podocyte progenitors have been identified, including renin lineage cells, which can become podocytes or PECs. ${ }^{115}$ In transgenic reporter mice, a significant increase in the numbers of genetically fate-mapped, renin-expressing cells occurred in the glomerulus after podocyte depletion. Enrichment of a subset of these cells, which expressed markers of both PECs and podocytes, was enhanced by glucocorticoid treatment, which also resulted in a reduction in sclerosis and an increase in podocyte number. These findings support a beneficial transition of renin lineage cells to podocytes after injury. In a rat model of ageingassociated FSGS, loss of podocytes and an increase in the number of cells that expressed PEC markers, such as Pax-2 and claudin-1, were observed. ${ }^{116}$ With calorie restriction, abnormal glomerular hypertrophy did not develop and no shift in numbers of podocytes and PECs occurred.

\section{Impairment of autophagy}

Autophagy - the process whereby lysosomes degrade and recycle cytosolic components (including proteins, lipids and organelles)—is a major mechanism of cellular homeostasis and repair after injury. Impaired autophagy may be particularly crucial in determining the consequences of injury in cells with limited regenerative capacity, such as podocytes. Autophagy is regulated in part by the mTOR-serine/threonine-protein kinase ULK1 pathway; thus inhibition of this pathway using rapamycin resulted in upregulation of autophagy and a decrease in injury in PAN-treated podocytes. ${ }^{117}$ Disruption of autophagy in podocytes in mice (by deletion of the mammalian homologue of phosphatidylinositol 3kinase VPS34 [also known as yeast vacuolar protein sorting defective 34]), resulted in the development of severe sclerosis, with increased autophagosomes in podocytes, elevated lysosome-specific markers (lysosome-associated membrane glycoprotein [LAMP] 1 and LAMP2) and autophagosome-specific markers (autophagy-related protein LC3-II and LC3I) and complete foot-process effacement. ${ }^{118}$ 
A distinct cytoplasmic compartment that may modulate mTOR complex activity and interaction with autophagy in podocytes has been identified. ${ }^{119,120}$ This TOR-autophagy spatial coupling compartment is located at the trans-side of the Golgi apparatus and is enriched with increased amounts of mTOR and autolysosomes. Such compartmentalization enables simultaneous activation of the mTOR pathway and autophagy within the cell, and thus is important for response to injury and for repair. ${ }^{119}$

\section{Proteinuria}

Proteinuria may not merely be a marker of glomerular injury and loss of podocyte permselectivity; it has been implicated in tubulointerstitial fibrosis by activating inflammatory and/or profibrotic pathways in tubular cells ${ }^{121}$ and might also injure podocytes. ${ }^{122}$ After initial adriamycin-induced injury in mice, leakage of protein across the capillary wall was associated with sequestering of retinoic acid, which resulted in impaired binding of retinoic acid to the retinoic acid response element (RARE). As RARE may mediate transcription of some podocyte-specific genes, a decrease in its activity could prevent differentiation of podocytes. Conversely, when animals were treated with retinoic acid, the pathway was restored and podocyte number increased. ${ }^{122}$

\section{Conclusions}

In summary, FSGS has diverse manifestations and mechanisms. Key susceptibility factors to develop glomerulosclerosis include APOL1 risk alleles, low birth weight and congenital or acquired reduced nephron number. Further elucidation of circulating-factor-induced podocyte injury may shed light on mechanisms of podocyte injury in primary FSGS. Loss of podocytes and potential sources and mechanisms of replenishment and rescue of injured podocytes are key areas for ongoing study. Understanding the complex cross-talk of glomerular cells, including endothelial cells, mesangial cells PECs and podocytes, will potentially enable targeted restoration of glomerular homeostasis and promote healing after injury rather than progressive sclerosis. Thus, insights into the specific cellular perturbations in various forms of FSGS may result in translation from altered molecular pathways to therapeutic targets for repair.

\section{Acknowledgments}

The author's work is supported in part by NIDDK grant R01 DK445757. She also thanks Dr Haichun Yang for his technical assistance and helpful comments.

\section{References}

1. Collins AJ, et al. US Renal Data System 2010 Annual Data Report. Am. J. Kidney Dis. 2011; 57(Suppl. 1):e1-e526.

2. D’Agati VD, Kaskel FJ, Falk RJ. Focal segmental glomerulosclerosis. N. Engl. J. Med. 2011; 365:2398-2411. [PubMed: 22187987]

3. Hogan J, Radhakrishnan J. The treatment of minimal change disease in adults. J. Am. Soc. Nephrol. 2013; 24:702-711. [PubMed: 23431071]

4. Verani RR, Hawkins EP. Recurrent focal segmental glomerulosclerosis A pathological study of the early lesion. Am. J. Nephrol. 1986; 6:263-270. [PubMed: 3535503] 
5. Straatmann C, et al. Success with plasmapheresis treatment for recurrent focal segmental glomerulosclerosis in pediatric renal transplant recipients. Pediatr. Transplant. 2014; 18:29-34. [PubMed: 24266922]

6. Gallon L, Leventhal J, Skaro A, Kanwar Y, Alvarado A. Resolution of recurrent focal segmental glomerulosclerosis after retransplantation. N. Engl. J. Med. 2012; 366:1648-1649. [PubMed: 22533598]

7. Vinai M, Waber P, Seikaly MG. Recurrence of focal segmental glomerulosclerosis in renal allograft: an in-depth review. Pediatr. Transplant. 2010; 14:314-325. [PubMed: 20519016]

8. D’Agati VD, Fogo AB, Bruijn JA, Jennette JC. Pathologic classification of focal segmental glomerulosclerosis: a working proposal. Am. J. Kidney Dis. 2004; 43:368-382. [PubMed: 14750104]

9. Barisoni L, Kriz W, Mundel P, D’Agati V. The dysregulated podocyte phenotype: a novel concept in the pathogenesis of collapsing idiopathic focal segmental glomerulosclerosis and HIV-associated nephropathy. J. Am. Soc. Nephrol. 1999; 10:51-61. [PubMed: 9890309]

10. Howie AJ, Brewer DB. Further studies on the glomerular tip lesion: early and late stages and life table analysis. J. Pathol. 1985; 147:245-255. [PubMed: 4087076]

11. Howie AJ, Pankhurst T, Sarioglu S, Turhan N, Adu D. Evolution of nephrotic-associated focal segmental glomerulosclerosis and relation to the glomerular tip lesion. Kidney Int. 2005; 67:9871001. [PubMed: 15698437]

12. Stokes MB, Valeri AM, Markowitz GS, D'Agati VD. Cellular focal segmental glomerulosclerosis: clinical and pathologic features. Kidney Int. 2006; 70:1783-1792. [PubMed: 17021605]

13. Thomas DB, et al. Clinical and pathologic characteristics of focal segmental glomerulosclerosis pathologic variants. Kidney Int. 2006; 69:920-926. [PubMed: 16518352]

14. IJpelaar DHT, et al. Fidelity and evolution of recurrent FSGS in renal allografts. J. Am. Soc. Nephrol. 2008; 19:2219-2224. [PubMed: 18579640]

15. Canaud G, et al. Recurrence of nephrotic syndrome after transplantation in a mixed population of children and adults: course of glomerular lesions and value of the Columbia classification of histological variants of focal and segmental glomerulosclerosis (FSGS). Nephrol. Dial. Transplant. 2010; 25:1321-1328. [PubMed: 19773419]

16. Rossini M, Fogo AB. Interpreting segmental glomerular sclerosis. Curr. Diagnostic Pathol. 2004; 10:1-10.

17. D'Agati VD, et al. Association of histologic variants in FSGS clinical trial with presenting features and outcomes. Clin. J. Am. Soc. Nephrol. 2013; 8:399-406. [PubMed: 23220425]

18. Mondini A, Messa P, Rastaldi MP. The sclerosing glomerulus in mice and man: novel insights. Curr. Opin. Nephrol. Hypertens. 2014; 23:239-244. [PubMed: 24709948]

19. McCarthy ET, Sharma M, Savin VJ. Circulating permeability factors in idiopathic nephrotic syndrome and focal segmental glomerulosclerosis. Clin. J. Am. Soc. Nephrol. 2010; 5:2115-2121. [PubMed: 20966123]

20. Wei C, et al. Circulating urokinase receptor as a cause of focal segmental glomerulosclerosis. Nat. Med. 2011; 17:952-960. [PubMed: 21804539]

21. Jefferson JA, Shankland SJ. Has the circulating permeability factor in primary FSGS been found? Kidney Int. 2013; 84:235-238. [PubMed: 23903418]

22. Huang J, et al. Plasma soluble urokinase receptor levels are increased but do not distinguish primary from secondary focal segmental glomerulosclerosis. Kidney Int. 2013; 84:366-372. [PubMed: 23447064]

23. Bock ME, Price HE, Gallon L, Langman CB. Serum soluble urokinase-type plasminogen activator receptor levels and idiopathic FSGS in children: a single-center report. Clin. J. Am. Soc. Nephrol. 2013; 8:1304-1311. [PubMed: 23620441]

24. Franco Palacios CR, et al. Urine but not serum soluble urokinase receptor (suPAR) may identify cases of recurrent FSGS in kidney transplant candidates. Transplantation. 2013; 96:394-399. [PubMed: 23736353]

25. Meijers B, et al. The soluble urokinase receptor is not a clinical marker for focal segmental glomerulosclerosis. Kidney Int. 2014; 85:636-640. [PubMed: 24402090] 
26. Sinha A, et al. Serum-soluble urokinase receptor levels do not distinguish focal segmental glomerulosclerosis from other causes of nephrotic syndrome in children. Kidney Int. 2014; 85:649-658. [PubMed: 24429405]

27. Kronbichler A, et al. Rituximab treatment for relapsing minimal change disease and focal segmental glomerulosclerosis: a systematic review. Am. J. Nephrol. 2014; 39:322-330. [PubMed: 24751753]

28. Pollak MR. The genetic basis of FSGS and steroid-resistant nephrosis. Semin. Nephrol. 2003; 23:141-146. [PubMed: 12704574]

29. Gbadegesin R, et al. Mutational analysis of NPHS2 and WT1 in frequently relapsing and steroiddependent nephrotic syndrome. Pediatr. Nephrol. 2007; 22:509-513. [PubMed: 17216259]

30. Gigante M, et al. CD2AP mutations are associated with sporadic nephrotic syndrome and focal segmental glomerulosclerosis (FSGS). Nephrol. Dial. Transplant. 2009; 24:1858-1864. [PubMed: 19131354]

31. Kim JM, et al. CD2-associated protein haploinsufficiency is linked to glomerular disease susceptibility. Science. 2003; 300:1298-1300. [PubMed: 12764198]

32. Barua M, et al. Mutations in the INF2 gene account for a significant proportion of familial but not sporadic focal and segmental glomerulosclerosis. Kidney Int. 2013; 83:316-322. [PubMed: 23014460]

33. Choi HJ, et al. Familial focal segmental glomerulosclerosis associated with an ACTN4 mutation and paternal germline mosaicism. Am. J. Kidney Dis. 2008; 51:834-838. [PubMed: 18436095]

34. Ma LJ, Fogo AB. Model of robust induction of glomerulosclerosis in mice: importance of genetic background. Kidney Int. 2003; 64:350-355. [PubMed: 12787428]

35. Laouari D, et al. TGF-a mediates genetic susceptibility to chronic kidney disease. J. Am. Soc. Nephrol. 2011; 22:327-335. [PubMed: 21183591]

36. Papeta N, et al. Prkdc participates in mitochondrial genome maintenance and prevents Adriamycininduced nephropathy in mice. J. Clin. Invest. 2010; 120:4055-4064. [PubMed: 20978358]

37. Parsa A, et al. APOL1 risk variants, race, and progression of chronic kidney disease. N. Engl. J. Med. 2013; 369:2183-2196. [PubMed: 24206458]

38. Genovese G, et al. Association of trypanolytic ApoL1 variants with kidney disease in African Americans. Science. 2010; 329:841-845. [PubMed: 20647424]

39. Gebeshuber CA, et al. Focal segmental glomerulosclerosis is induced by microRNA-193a and its downregulation of WT1. Nat. Med. 2013; 19:481-487. [PubMed: 23502960]

40. Cavasin MA, Rhaleb NE, Yang XP, Carretero OA. Prolyl oligopeptidase is involved in release of the antifibrotic peptide Ac-SDKP. Hypertension. 2004; 43:1140-1145. [PubMed: 15037553]

41. Zuo Y, et al. Thymosin $\beta 4$ and its degradation product, Ac-SDKP, are novel reparative factors in renal fibrosis. Kidney Int. 2013; 84:1166-1175. [PubMed: 23739235]

42. Macconi D, et al. MicroRNA-324-3p promotes renal fibrosis and is a target of ACE inhibition. J. Am. Soc. Nephrol. 2012; 23:1496-1505. [PubMed: 22822076]

43. Wu J, et al. Downregulation of microRNA-30 facilitates podocyte injury and Is prevented by glucocorticoids. J. Am. Soc. Nephrol. 2014; 25:92-104. [PubMed: 24029422]

44. Shi S, et al. Smad2-dependent downregulation of miR-30 is required for TGF- $\beta$-induced apoptosis in podocytes. PLoS ONE. 2013; 8:e75572. [PubMed: 24086574]

45. D'Agati V. Pathologic classification of focal segmental glomerulosclerosis. Semin. Nephrol. 2003; 23:117-134. [PubMed: 12704572]

46. Markowitz GS, Nasr SH, Stokes MB, D'Agati VD. Treatment with IFN- $\alpha,-\beta$, or $-\gamma$ is associated with collapsing focal segmental glomerulosclerosis. Clin. J. Am. Soc. Nephrol. 2010; 5:607-615. [PubMed: 20203164]

47. Markowitz GS, et al. Collapsing focal segmental glomerulosclerosis following treatment with high-dose pamidronate. J. Am. Soc. Nephrol. 2001; 12:1164-1172. [PubMed: 11373339]

48. Faul $\mathrm{C}$, et al. The actin cytoskeleton of kidney podocytes is a direct target of the antiproteinuric effect of cyclosporine A. Nat. Med. 2008; 14:931-938. [PubMed: 18724379]

49. Meehan SM, et al. De novo collapsing glomerulopathy in renal allografts. Transplantation. 1998; 65:1192-1197. [PubMed: 9603167] 
50. Hunley TE, Fogo A, Iwasaki S, Kon V. Endothelin A receptor mediates functional but not structural damage in chronic cyclosporine nephrotoxicity. J. Am. Soc. Nephrol. 1995; 5:17181723. [PubMed: 7780063]

51. Fogo AB. The targeted podocyte. J. Clin. Invest. 2011; 121:2142-2145. [PubMed: 21606599]

52. Godel M, et al. Role of mTOR in podocyte function and diabetic nephropathy in humans and mice. J. Clin. Invest. 2011; 121:2197-2209. [PubMed: 21606591]

53. Herlitz LC, et al. Development of focal segmental glomerulosclerosis after anabolic steroid abuse. J. Am. Soc. Nephrol. 2010; 21:163-172. [PubMed: 19917783]

54. Cohen AH, Nast CC. HIV-associated nephropathy. A unique combined glomerular, tubular, and interstitial lesion. Mod. Pathol. 1988; 1:87-97. [PubMed: 3070550]

55. Marras D, et al. Replication and compartmentalization of HIV-1 in kidney epithelium of patients with HIV-associated nephropathy. Nat. Med. 2002; 8:522-526. [PubMed: 11984599]

56. Medapalli RK, He JC, Klotman PE. HIV-associated nephropathy: pathogenesis. Curr. Opin. Nephrol. Hypertens. 2011; 20:306-311. [PubMed: 21358326]

57. Zuo Y, et al. HIV-1 genes vpr and nef synergistically damage podocytes, leading to glomerulosclerosis. J. Am. Soc. Nephrol. 2006; 17:2832-2843. [PubMed: 16988066]

58. Zhong J, et al. Expression of HIV-1 genes in podocytes alone can lead to the full spectrum of HIV-1-associated nephropathy. Kidney Int. 2005; 68:1048-1060. [PubMed: 16105035]

59. Kopp JB, et al. APOL1 genetic variants in focal segmental glomerulosclerosis and HIV-associated nephropathy. J. Am. Soc. Nephrol. 2011; 22:2129-2137. [PubMed: 21997394]

60. Moudgil A, et al. Association of parvovirus B19 infection with idiopathic collapsing glomerulopathy. Kidney Int. 2001; 59:2126-2133. [PubMed: 11380814]

61. Hostetter TH, Olson JL, Rennke HG, Venkatachalam MA, Brenner BM. Hyperfiltration in remnant nephrons: a potentially adverse response to renal ablation. Am. J. Physiol. 1981; 241:F85-F93. [PubMed: 7246778]

62. Anderson S, Rennke HG, Brenner BM. Therapeutic advantage of converting enzyme inhibitors in arresting progressive renal disease associated with systemic hypertension in the rat. J. Clin. Invest. 1986; 77:1993-2000. [PubMed: 3011863]

63. Fogo A, et al. Glomerular hypertrophy in minimal change disease predicts subsequent progression to focal glomerular sclerosis. Kidney Int. 1990; 38:115-123. [PubMed: 2385079]

64. Fogo A, Yoshida Y, Glick AD, Homma T, Ichikawa I. Serial micropuncture analysis of glomerular function in two rat models of glomerular sclerosis. J. Clin. Invest. 1988; 82:322-330. [PubMed: 3392211]

65. Barker DJ, Osmond C. Low birth weight and hypertension. BMJ. 1988; 297:134-135. [PubMed: 3408942]

66. Luyckx VA, et al. Effect of fetal and child health on kidney development and long-term risk of hypertension and kidney disease. Lancet. 2013; 382:273-283. [PubMed: 23727166]

67. White SL, et al. Is low birth weight an antecedent of CKD in later life? A systematic review of observational studies. Am. J. Kidney Dis. 2009; 54:248-261. [PubMed: 19339091]

68. Hodgin JB, Rasoulpour M, Markowitz GS, D’Agati VD. Very low birth weight is a risk factor for secondary focal segmental glomerulosclerosis. Clin. J. Am. Soc. Nephrol. 2009; 4:71-76. [PubMed: 19019999]

69. Schulz LC. The Dutch Hunger Winter and the developmental origins of health and disease. Proc. Natl Acad. Sci. USA. 2010; 107:16757-16758. [PubMed: 20855592]

70. Ikezumi Y, et al. Low birthweight and premature birth are risk factors for podocytopenia and focal segmental glomerulosclerosis. Am. J. Nephrol. 2013; 38:149-157. [PubMed: 23920104]

71. Ma J, et al. Effects of podocyte injury on glomerular development. Pediatr. Res. 2007; 62:417-421. [PubMed: 17667850]

72. Bertram JF, Douglas-Denton RN, Diouf B, Hughson MD, Hoy WE. Human nephron number: implications for health and disease. Pediatr. Nephrol. 2011; 26:1529-1533. [PubMed: 21604189]

73. Zimanyi MA, et al. Nephron number and individual glomerular volumes in male Caucasian and African American subjects. Nephrol. Dial. Transplant. 2009; 24:2428-2433. [PubMed: 19297355] 
74. Hoy WE, Hughson MD, Singh GR, Douglas-Denton R, Bertram JF. Reduced nephron number and glomerulomegaly in Australian Aborigines: a group at high risk for renal disease and hypertension. Kidney Int. 2006; 70:104-110. [PubMed: 16723986]

75. Fogo AB. Glomerular hypertension, abnormal glomerular growth, and progression of renal diseases. Kidney Int. Suppl. 2000; 75:S15-S21. [PubMed: 10828756]

76. Wikstad I, Celsi G, Larsson L, Herin P, Aperia A. Kidney function in adults born with unilateral renal agenesis or nephrectomized in childhood. Pediatr. Nephrol. 1988; 2:177-182. [PubMed: 3153008]

77. Fowler SM, et al. Obesity-related focal and segmental glomerulosclerosis: normalization of proteinuria in an adolescent after bariatric surgery. Pediatr. Nephrol. 2009; 24:851-855. [PubMed: 18941798]

78. Kambham N, Markowitz GS, Valeri AM, Lin J, D’Agati VD. Obesity-related glomerulopathy: an emerging epidemic. Kidney Int. 2001; 59:1498-1509. [PubMed: 11260414]

79. Schmid H, et al. Gene expression profiles of podocyte-associated molecules as diagnostic markers in acquired proteinuric diseases. J. Am. Soc. Nephrol. 2003; 14:2958-2966. [PubMed: 14569107]

80. Xu BJ, et al. Proteomic patterns and prediction of glomerulosclerosis and its mechanisms. J. Am. Soc. Nephrol. 2005; 16:2967-2975. [PubMed: 16079267]

81. Durvasula RV, Shankland SJ. The renin-angiotensin system in glomerular podocytes: mediator of glomerulosclerosis and link to hypertensive nephropathy. Curr. Hypertens. Rep. 2006; 8:132-138. [PubMed: 16672146]

82. Naito T, et al. Angiotensin type 2 receptor actions contribute to angiotensin type 1 receptor blocker effects on kidney fibrosis. Am. J. Physiol. Renal Physiol. 2010; 298:F683-F691. [PubMed: 20042458]

83. Wu DT, Bitzer M, Ju W, Mundel P, Bottinger EP. TGF- $\beta$ concentration specifies differential signaling profiles of growth arrest/differentiation and apoptosis in podocytes. J. Am. Soc. Nephrol. 2005; 16:3211-3221. [PubMed: 16207831]

84. Eddy AA, Fogo AB. Plasminogen activator inhibitor-1 in chronic kidney disease: evidence and mechanisms of action. J. Am. Soc. Nephrol. 2006; 17:2999-3012. [PubMed: 17035608]

85. Ma LJ, Fogo AB. PAI-1 and kidney fibrosis. Front. Biosci. (Landmark Ed.). 2009; 14:2028-2041. [PubMed: 19273183]

86. Fogo AB. Mechanisms of progression of chronic kidney disease. Pediatr. Nephrol. 2007; 22:20112022. [PubMed: 17647026]

87. Regele HM, et al. Glomerular expression of dystroglycans is reduced in minimal change nephrosis but not in focal segmental glomerulosclerosis. J. Am. Soc. Nephrol. 2000; 11:403-412. [PubMed: 10703664]

88. Giannico G, Yang H, Neilson EG, Fogo AB. Dystroglycan in the diagnosis of FSGS. Clin. J. Am. Soc. Nephrol. 2009; 4:1747-1753. [PubMed: 19808230]

89. Giannico G, et al. Dystroglycan patterns in FSGS variants. Lab. Invest. 2011; 91:344A.

90. Lasagni L, Lazzeri E, Shankland SJ, Anders HJ, Romagnani P. Podocyte mitosis - a catastrophe. Curr. Mol. Med. 2013; 13:13-23. [PubMed: 23176147]

91. Kriz W, Gretz N, Lemley KV. Progression of glomerular diseases: is the podocyte the culprit? Kidney Int. 1998; 54:687-697. [PubMed: 9734594]

92. Wharram BL, et al. Podocyte depletion causes glomerulosclerosis: diphtheria toxin-induced podocyte depletion in rats expressing human diphtheria toxin receptor transgene. J. Am. Soc. Nephrol. 2005; 16:2941-2952. [PubMed: 16107576]

93. Matsusaka T, et al. Podocyte injury damages other podocytes. J. Am. Soc. Nephrol. 2011; 22:1275-1285. [PubMed: 21719786]

94. Matsusaka T, et al. Glomerular sclerosis is prevented during urinary tract obstruction due to podocyte protection. Am. J. Physiol. Renal Physiol. 2011; 300:F792-F800. [PubMed: 21177778]

95. Eremina V, et al. VEGF inhibition and renal thrombotic microangiopathy. N. Engl. J. Med. 2008; 358:1129-1136. [PubMed: 18337603]

96. Eremina V, et al. Glomerular-specific alterations of VEGF-A expression lead to distinct congenital and acquired renal diseases. J. Clin. Invest. 2003; 111:707-716. [PubMed: 12618525] 
97. Shankland SJ, Smeets B, Pippin JW, Moeller MJ. The emergence of the glomerular parietal epithelial cell. Nat. Rev. Nephrol. 2014; 10:158-173. [PubMed: 24468766]

98. Lasagni L, Romagnani P. Basic research: Podocyte progenitors and ectopic podocytes. Nat. Rev. Nephrol. 2013; 9:715-716. [PubMed: 24217462]

99. Shankland SJ, Anders HJ, Romagnani P. Glomerular parietal epithelial cells in kidney physiology, pathology, and repair. Curr. Opin. Nephrol. Hypertens. 2013; 22:302-309. [PubMed: 23518463]

100. Berger K, et al. The regenerative potential of parietal epithelial cells in adult mice. J. Am. Soc. Nephrol. 2014; 25:693-705. [PubMed: 24408873]

101. Ueno T, et al. Aberrant Notch1-dependent effects on glomerular parietal epithelial cells promotes collapsing focal segmental glomerulosclerosis with progressive podocyte loss. Kidney Int. 2013; 83:1065-1075. [PubMed: 23447065]

102. Sugimoto $\mathrm{H}$, et al. Bone-marrow-derived stem cells repair basement membrane collagen defects and reverse genetic kidney disease. Proc. Natl Acad. Sci. USA. 2006; 103:7321-7326. [PubMed: $16648256]$

103. Meyer-Schwesinger C, et al. Bone marrow-derived progenitor cells do not contribute to podocyte turnover in the puromycin aminoglycoside and renal ablation models in rats. Am. J. Pathol. 2011; 178:494-499. [PubMed: 21281782]

104. Smeets B, et al. Parietal epithelial cells participate in the formation of sclerotic lesions in focal segmental glomerulosclerosis. J. Am. Soc. Nephrol. 2011; 22:1262-1274. [PubMed: 21719782]

105. Nagata M, Nakayama K, Terada Y, Hoshi S, Watanabe T. Cell cycle regulation and differentiation in the human podocyte lineage. Am. J. Pathol. 1998; 153:1511-1520. [PubMed: 9811343]

106. Sayyed SG, et al. Podocytes produce homeostatic chemokine stromal cell-derived factor-1/ CXCL12, which contributes to glomerulosclerosis, podocyte loss and albuminuria in a mouse model of type 2 diabetes. Diabetologia. 2009; 52:2445-2454. [PubMed: 19707743]

107. Shkreli M, et al. Reversible cell-cycle entry in adult kidney podocytes through regulated control of telomerase and Wnt signaling. Nat. Med. 2012; 18:111-119. [PubMed: 22138751]

108. Niranjan T, et al. The Notch pathway in podocytes plays a role in the development of glomerular disease. Nat. Med. 2008; 14:290-298. [PubMed: 18311147]

109. Fatima H, et al. Parietal epithelial cell activation marker in early recurrence of FSGS in the transplant. Clin. J. Am. Soc. Nephrol. 2012; 7:1852-1858. [PubMed: 22917699]

110. Rizzo P, et al. Nature and mediators of parietal epithelial cell activation in glomerulonephritides of human and rat. Am. J. Pathol. 2013; 183:1769-1778. [PubMed: 24095923]

111. Ren G, Khusheim M, Yang H, Fogo AB. Plasminogen activator inhibitor-1 (PAI-1) affects parietal epithelial cell (PECs) transition. Lab. Invest. 2013; 93:391A.

112. Palma Diaz M, et al. Expansion of the parietal cell compartment in collapsing glomerulopathy. Lab. Invest. 2011; 91:349A.

113. Sakamoto K, et al. The direction and role of phenotypic transition between podocytes and parietal epithelial cells in focal segmental glomerulosclerosis. Am. J. Physiol. Renal Physiol. 2014; 306:F98-F104. [PubMed: 24154691]

114. Wanner N, et al. Unraveling the role of podocyte turnover in glomerular aging and injury. J. Am. Soc. Nephrol. 2014; 25:707-716. [PubMed: 24408871]

115. Pippin JW, et al. Cells of renin lineage are progenitors of podocytes and parietal epithelial cells in experimental glomerular disease. Am. J. Pathol. 2013; 183:542-557. [PubMed: 23769837]

116. Zhang J, et al. De novo expression of podocyte proteins in parietal epithelial cells in experimental aging nephropathy. Am. J. Physiol. Renal Physiol. 2012; 302:F571-F580. [PubMed: 22129965]

117. Wu L, et al. Rapamycin upregulates autophagy by inhibiting the mTOR-ULK1 pathway, resulting in reduced podocyte injury. PLoS ONE. 2013; 8:e63799. [PubMed: 23667674]

118. Chen J, Chen MX, Fogo AB, Harris RC, Chen JK. mVps34 deletion in podocytes causes glomerulosclerosis by disrupting intracellular vesicle trafficking. J. Am. Soc. Nephrol. 2013; 24:198-207. [PubMed: 23291473]

119. Huber TB, et al. Emerging role of autophagy in kidney function, diseases and aging. Autophagy. 2012; 8:1009-1031. [PubMed: 22692002] 
120. Narita M, et al. Spatial coupling of mTOR and autophagy augments secretory phenotypes. Science. 2011; 332:966-970. [PubMed: 21512002]

121. Zoja C, Benigni A, Remuzzi G. Cellular responses to protein overload: key event in renal disease progression. Curr. Opin. Nephrol. Hypertens. 2004; 13:31-37. [PubMed: 15090857]

122. Peired A, et al. Proteinuria impairs podocyte regeneration by sequestering retinoic acid. J. Am. Soc. Nephrol. 2013; 24:1756-1768. [PubMed: 23949798] 


\section{Key points}

- Podocyte injury and loss are key events in the development of progressive glomerulosclerosis

- $\quad$ The term focal segmental glomerulosclerosis (FSGS) refers to a disease of primary podocyte injury, or a lesion caused by secondary scarring processes in any type of chronic kidney disease

- $\quad$ FSGS lesions can occur as a result of many causes, including circulating factors, underlying mutations in key podocyte genes, drug use, infection and maladaptive responses to nephron loss

- Premature birth, profibrotic molecules, autophagy and proteinuria might have roles in the pathogenesis of FSGS

- Parietal epithelial cells are potential podocyte progenitors that, depending on the microenvironment, might replace injured podocytes or contribute to the scarring response and podocyte loss 

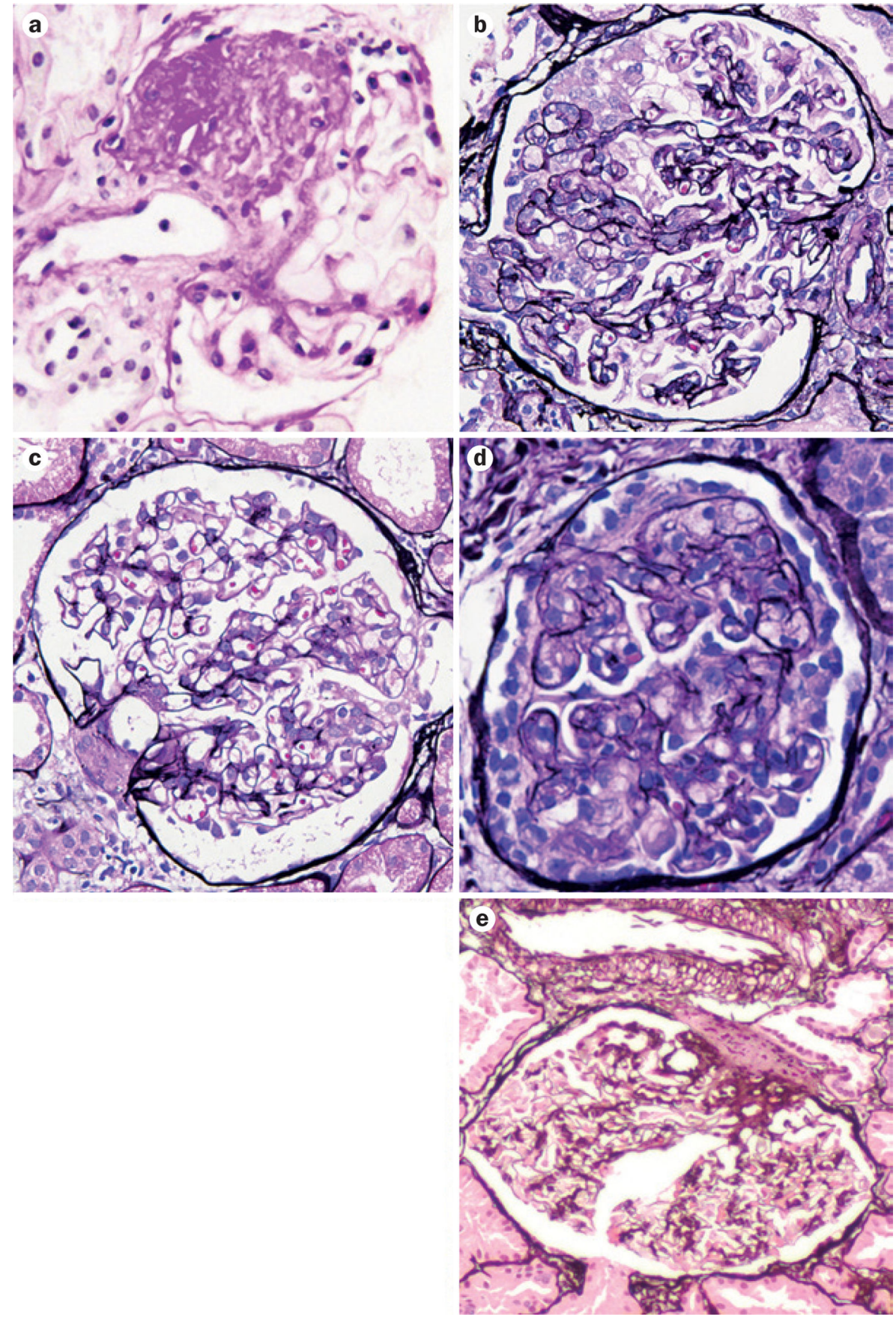

Figure 1.

FSGS lesions have varying morphologic appearances. a | Not otherwise specified type with obliteration of segmental areas of the glomerular capillary tuft by increased matrix. b | Collapsing type, with proliferation of visceral epithelial cells and collapse of the tuft. c | Tip lesion with adhesion and/or sclerosis at the proximal tubular pole (right). d $\mid$ Cellular, with increased endocapillary cells. e | Hilar, with sclerosis with or without hyalinosis at the vascular pole. Stains: part a, periodic acid Schiff; parts b-e, Jones' silver. Abbreviation: FSGS, focal segmental glomerulosclerosis. 

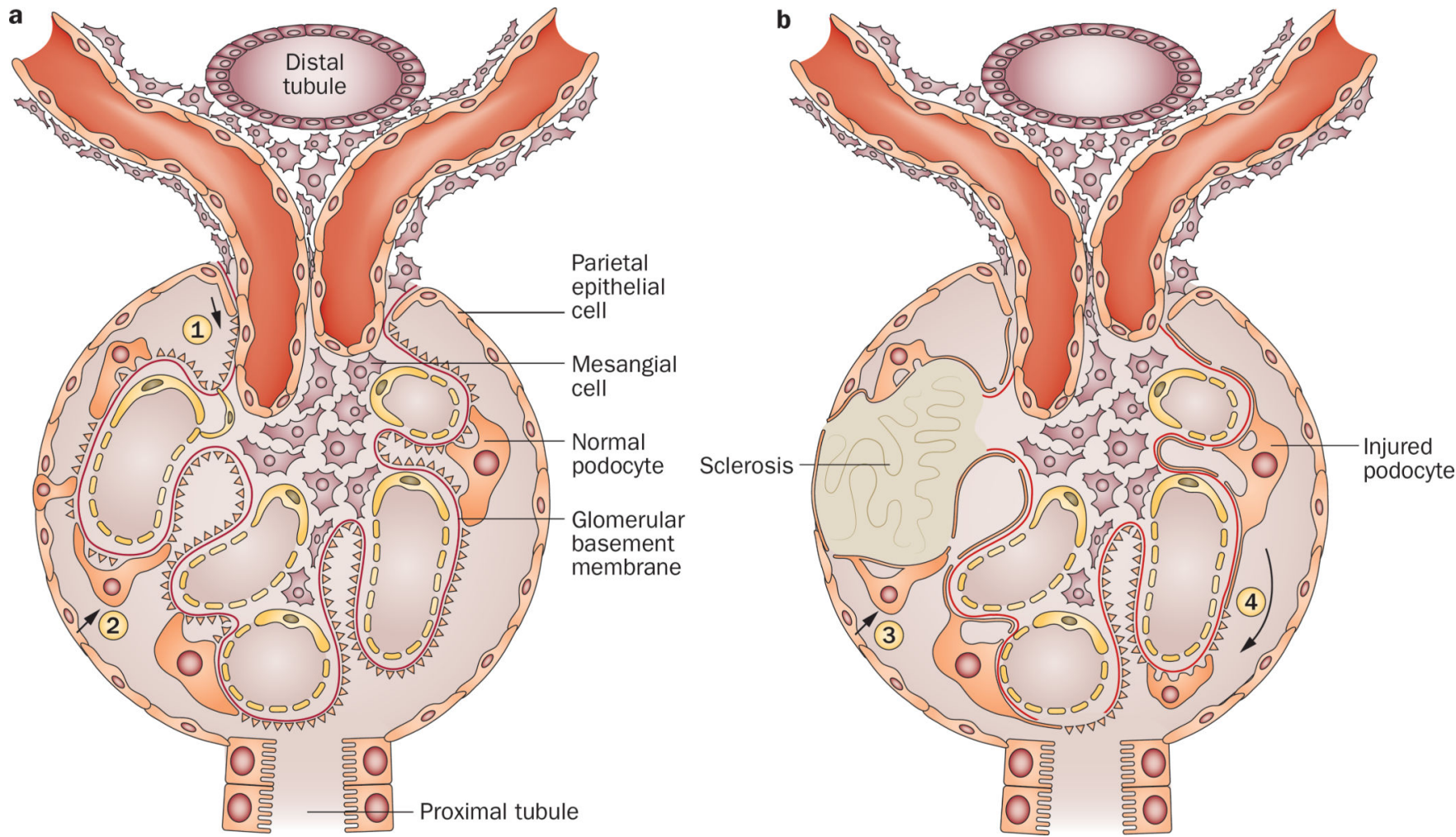

Figure 2.

Possible pathways for regeneration of podocytes from PEC migration to the glomerular tuft and for the development of sclerosis. a During embryonic development, or after severe acute injury in young mice, PEC migration to the tuft from the vascular pole (1) or via early adhesions (2) may replenish injured podocytes and prevent further podocyte loss and sclerosis. $\mathbf{b} \mid$ In older mice, or after secondary injury due to nephron loss, PEC migration does not result in restoration of podocytes, but rather progressive sclerosis (3). Further, segmental podocyte injury may spread to initially spared podocytes (4), especially if ongoing filtration is occurring. Manipulation of other potential stem cells or the microenvironment may modulate these responses. Abbreviation: PEC, parietal epithelial cell. 


\section{Table 1}

Working classification of FSGS ${ }^{63}$

\begin{tabular}{lll}
\hline Type & Key histologic feature & $\begin{array}{l}\text { Possible prognostic } \\
\text { implication }\end{array}$ \\
\hline $\begin{array}{l}\text { FSGS not otherwise } \\
\text { specified }\end{array}$ & Segmental sclerosis & Typical course \\
\hline Collapsing FSGS & $\begin{array}{l}\text { Collapse of tuft, podocyte } \\
\text { hyperplasia }\end{array}$ & Poor prognosis \\
\hline Cellular FSGS & $\begin{array}{l}\text { Endocapillary proliferation, } \\
\text { often podocyte hyperplasia }\end{array}$ & Early stage lesion? \\
\hline Tip lesion & $\begin{array}{l}\text { Sclerosis of tuft at proximal } \\
\text { tubule pole }\end{array}$ & Better prognosis? \\
\hline Perihilar variant & $\begin{array}{l}\text { Sclerosis and hyalinosis at } \\
\text { vascular pole }\end{array}$ & $\begin{array}{l}\text { May reflect a secondary } \\
\text { type of FSGS }\end{array}$ \\
\hline
\end{tabular}

Abbreviation: FSGS, focal segmental glomerulosclerosis. 
Table 2

Genetic causes of FSGS and/or nephrotic syndrome

\begin{tabular}{|c|c|c|c|}
\hline Gene & Protein & Function & Phenotype \\
\hline NPHSI & Nephrin & Podocyte slit diaphragm & $\begin{array}{l}\text { Congenital nephrotic syndrome Finnish type, } \\
\text { sporadic FSGS or nephrotic syndrome }\end{array}$ \\
\hline$C D 2 A P$ & $\mathrm{CD} 2$-associated protein & Podocyte slit diaphragm & $\begin{array}{l}\text { Autosomal-dominant or autosomal-recessive } \\
\text { sporadic adult-onset FSGS }\end{array}$ \\
\hline NPHS2 & Podocin & Podocyte slit diaphragm & Early onset autosomal-recessive FSGS \\
\hline ACTN4 & a-actinin-4 & Podocyte cytoskeleton & Adult onset autosomal-dominant FSGS \\
\hline MYOIE & Unconventional myosin $1 \mathrm{E}$ & Actin function & Early onset autosomal-recessive FSGS \\
\hline$I N F 2$ & Inverted formin-2 & Actin regulation & Adult onset FSGS \\
\hline PTPRO & $\begin{array}{l}\text { Receptor-type tyrosine-protein } \\
\text { phosphatase } 0 *\end{array}$ & Podocyte signalling & Autosomal-recessive childhood FSGS \\
\hline ARHGDIA & Rho GDP-dissociation inhibitor 1 & $\begin{array}{l}\text { Rho GTPase signalling, } \\
\text { actin dynamics }\end{array}$ & Early onset nephrotic syndrome or FSGS \\
\hline TRPC6 & $\begin{array}{l}\text { Transient receptor potential } \\
\text { channel } 6\end{array}$ & $\begin{array}{l}\text { Calcium channel, podocyte } \\
\text { mechanosensing }\end{array}$ & $\begin{array}{l}\text { Autosomal-dominant or autosomal-recessive } \\
\text { sporadic adult onset FSGS }\end{array}$ \\
\hline$W T 1$ & Wilms tumour protein & Podocyte development & $\begin{array}{l}\text { Autosomal-dominant sporadic FSGS, diffuse } \\
\text { mesangial sclerosis }\end{array}$ \\
\hline PLCE1 & Phospholipase $\mathrm{C} \varepsilon 1$ & $\begin{array}{l}\text { Podocyte differentiation, } \\
\text { signalling }\end{array}$ & $\begin{array}{l}\text { Early onset autosomal-recessive FSGS } \\
\text { or diffuse mesangial sclerosis }\end{array}$ \\
\hline$L M X 1 B$ & $\begin{array}{l}\text { LIM homeobox transcription } \\
\text { factor } 1-\beta\end{array}$ & Podocyte and GBM development & Nail-patella syndrome, rare FSGS \\
\hline$C D 151$ & CD151 antigen & $\begin{array}{l}\text { Podocyte and GBM, laminin- } \\
\text { integrin interactions }\end{array}$ & Early FSGS, deafness, $\beta$-thalassemia \\
\hline$L A M B 2$ & Laminin B2 chain & $\begin{array}{l}\text { Interacts with integrin } a 3 \beta 1, \\
\text { links GBM to actin cytoskeleton }\end{array}$ & $\begin{array}{l}\text { Autosomal-recessive Pierson syndrome } \\
\text { or FSGS }\end{array}$ \\
\hline ITGB4 & Integrin $\beta 4$ & Cell-matrix adhesion & Rare FSGS \\
\hline SMARCAL1 & $\begin{array}{l}\text { SWI/SNF-related matrix-associated } \\
\text { actin-dependent regulator of } \\
\text { chromatin subfamily A-like protein } 1\end{array}$ & $\begin{array}{l}\text { Chromatin bundling and } \\
\text { gene transcription }\end{array}$ & $\begin{array}{l}\text { Autosomal-recessive Schimke immunoosseous } \\
\text { dysplasia, childhood FSGS }\end{array}$ \\
\hline COQ2 & Polyprenyltransferase & $\begin{array}{l}\text { Mitochondrial function, deficient } \\
\text { Coenzyme Q10 }\end{array}$ & $\begin{array}{l}\text { Autosomal-recessive early onset nephrotic } \\
\text { syndrome or FSGS }\end{array}$ \\
\hline COQ6 & $\begin{array}{l}\text { Ubiquinone biosynthesis } \\
\text { monooxygenase COQ6 }\end{array}$ & Ubiquinone biosynthesis & $\begin{array}{l}\text { Autosomal-recessive nephrotic syndrome, } \\
\text { FSGS, deafness }\end{array}$ \\
\hline PDSS2 & $\begin{array}{l}\text { Decaprenyl diphosphate synthase } \\
\text { subunit } 2\end{array}$ & $\begin{array}{l}\text { Coenzyme Q10 synthesis, } \\
\text { mitochondrial function }\end{array}$ & FSGS or collapsing FSGS \\
\hline$A D C K 4$ & $\begin{array}{l}\text { AarF domain-containing protein } \\
\text { kinase } 4\end{array}$ & Coenzyme Q10 modulation & FSGS \\
\hline MTTL1 & $\begin{array}{l}\text { Mitochondrially encoded tRNA } \\
\text { leucine } 1\end{array}$ & Mitochondrial tRNA & Autosomal recessive MELAS or FSGS \\
\hline SCARB2 & $\begin{array}{l}\text { Scavenger receptor class B } \\
\text { member } 2\end{array}$ & Putative lysosomal receptor & FSGS or collapsing FSGS \\
\hline$A P O L 1$ & Apolipoprotein L1 & Function unknown & Risk of FSGS, collapsing FSGS or HIVAN \\
\hline
\end{tabular}

* Also known as glomerular epithelial protein 1. Abbreviations: FSGS, focal segmental glomerulosclerosis; GBM, glomerular basement membrane; HIVAN, HIV-associated nephropathy; MELAS, mitochondrial myopathy, encephalopathy, lactic acidosis and stroke-like episodes. 